\title{
Rhipicephalus sanguineus sensu lato from dogs and dromedary camels in Riyadh, Saudi Arabia: low prevalence of vector-borne pathogens in dogs detected using multiplexed tandem PCR panel
}

\author{
Shona Chandra ${ }^{1, *}$, Karen Smith ${ }^{1, *}$, Abdullah D. Alanazi ${ }^{2}$, Mohamed S. Alyousif ${ }^{3}$, David Emery ${ }^{1}$ and Jan $\breve{S ̆ l a p e t a}^{1}$ \\ ${ }^{1}$ Sydney School of Veterinary Science, Faculty of Science, University of Sydney, Sydney, New South Wales, Australia; \\ ${ }^{2}$ Department of Biological Sciences, Faculty of Science and Humanities, Shaqra University, Ad-Dawadimi, Saudi Arabia; \\ ${ }^{3}$ Department of Zoology, College of Science, King Saud University, Riyadh, Saudi Arabia \\ * contributed equally
}

\begin{abstract}
Despite the global distribution of the brown dog tick, Rhipicephalus sanguineus (Latreille, 1806) sensu lato (s.1.), limited information exists about their identity from the Arabian Peninsula. Ticks from free roaming urban dogs and dromedary camels in Riyadh, Saudi Arabia were morphologically identified, confirmed with scanning electron microscopy and characterised at mitochondrial DNA (cox $1,12 \mathrm{~S}$ rDNA and 16S rDNA). A total of 186 ticks were collected from 65 free roaming dogs $(n=73)$ and 84 dromedary camels ( $n=113)$. Morphologically, 5.9\% (11/186) were R. sanguineus s.l. and Hyalomma spp. (93.5\%, 174/186). From within $R$. sanguineus s.l., the presence of Rhipicephalus cf. camicasi Morel, Mouchet et Rodhain, 1976 (1 dog, 2 camels) and Rhipicephalus turanicus Pomerantsev, 1936 ( 1 camel) is reported. The examined $R$. cf. camicasi form a sister group to $R$. sanguineus s.l. tropical lineage at all DNA markers. Dogs were parasitised by Hyalomma dromedarii Koch, $1844(n=59)$, Hyalomma impeltatum Schulze et Schlottke, 1930 $(n=1)$, Hyalomma excavatum Koch, $1844(n=2)$, Hyalomma turanicum Pomerantsev, $1946(n=1)$ and Hyalomma rufipes Koch,1844 $(n=1)$. DNA from dog blood $(n=53)$ from Riyadh confirmed a low prevalence of canine vector-borne pathogens that does not exceed 5.7\% for Babesia spp., Mycoplasma spp., Anaplasma platys, Hepatozoon canis and Ehrlichia canis using multiplexed tandem PCR (MT-PCR) and diagnostic PCR. Low prevalence of R. sanguineus s.l. on dogs likely contributed to the low level of canine vector-borne pathogens in Saudi Arabia. We demonstrate that dogs in the central Arabian Peninsula are more commonly parasitised by Hyalomma spp. than $R$. sanguineus s.1.
\end{abstract}

Keywords: brown dog tick, molecular identity, morphology, mtDNA, real-time PCR, SEM

Ticks (Acari: Ixodida) are significant, haematophagous ectoparasites of terrestrial and semi-aquatic animals (Roberts 1970, Walker et al. 2005, Dantas-Torres et al. 2013, Guglielmone et al. 2013, Barker and Walker 2014, Panetta et al. 2017). Ticks are important vectors for diseases and their global distribution contributes to the increase of emerging and re-emerging tick-borne diseases world-wide (Jongejan and Uilenberg 2004, Cutler 2010, Guglielmone et al. 2013, de la Fuente et al. 2017). The prevalence of vector-borne diseases in a population closely reflects the distribution and density of vectors (Aktas et al. 2015, Vascellari et al. 2016).

The brown dog tick, Rhipicephalus sanguineus, is the most significant contributor to the spread of tick-borne diseases in zoogeographical zones from latitude $50^{\circ} \mathrm{N}$ to $30^{\circ} \mathrm{S}$ (Leeson 1951, Hoogstraal et al. 1981, Walker et al. 2005, Dantas-Torres et al. 2013). Its spread has been attributed to its affinity for parasitising dogs and other canids (Leeson 1951, Guglielmone et al. 2013). In the past it was thought to be a single, globally distributed species, but it is now regarded as a complex of cryptic species (Pegram et al. 1987, Pegram and Walker 1988, Szabó et al. 2005, Walker et al. 2005). A neotype assignment for $R$. sanguineus enables the objective identification of the taxon and unless the identity matches the neotype of $R$. sanguineus sensu Nava et al. (2018), the brown dog ticks are referred as $R$. sanguineus sensu lato (s.1.).

The brown dog ticks have been subject to large number of identification surveys; nevertheless, many regions remain neglected or incompletely surveyed. No study has examined the identity of $R$. sanguineus s.l. and aetiology of canine vector-borne diseases in Saudi Arabia and limited information exists for the Arabian Peninsula (Pegram et al. 1982a, b, Pegram and Walker 1988, Rees et al. 2003, Kernif et al. 2012, Chitimia-Dobler et al. 2017). 
A
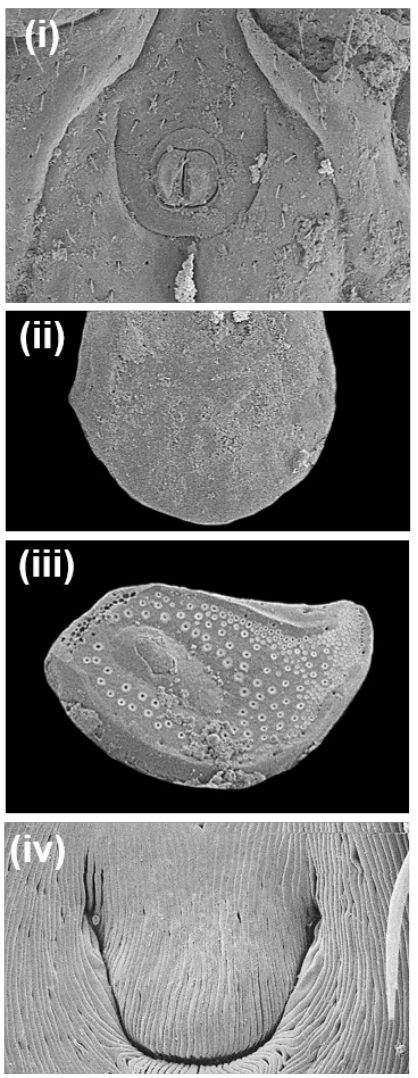

B
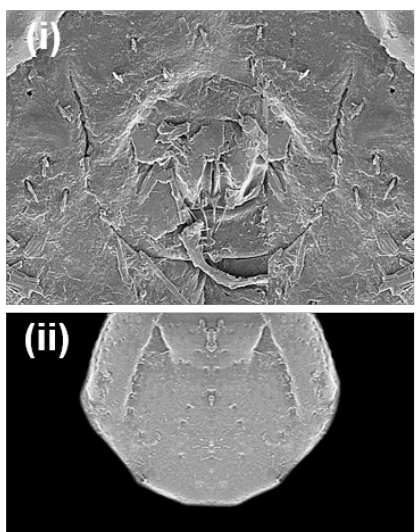

(iii)
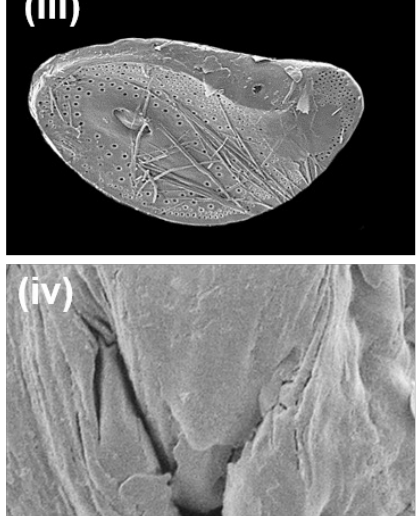

C
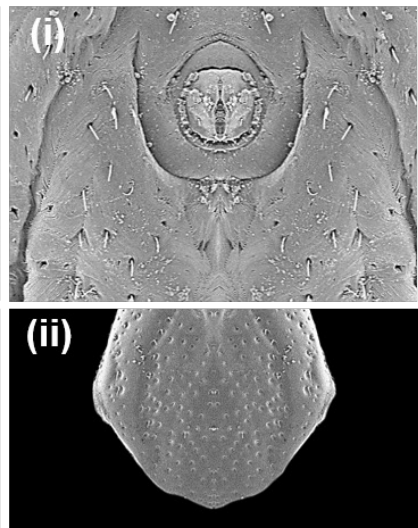

(iii)
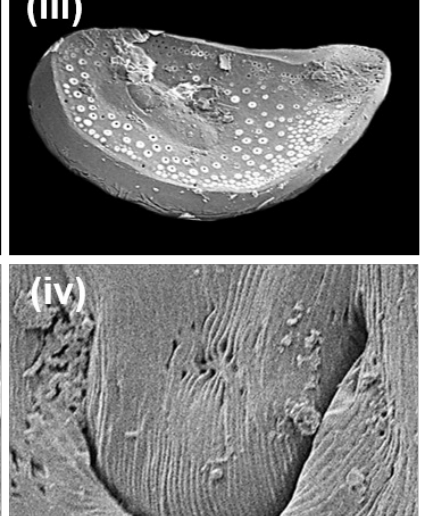

D
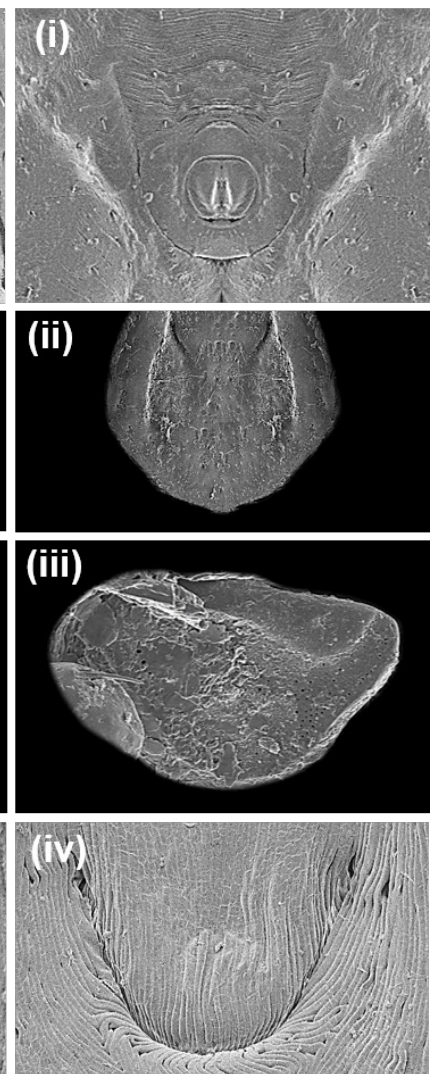

Fig. 1. Characteristics of female Rhipicephalus sanguineus s.l. tropical lineage (A) and Rhipicephalus cf. camicasi (B-D) as seen with SEM. Rhipicephalus sanguineus s.l. tropical lineage from Von Berky Veterinary Services, Australia as part of a laboratory raised colony and adult female Rhipicephalus cf. camicasi (B-D; SC0126-1, SC0127, SC0141) from Riyadh, Saudi Arabia are shown. U shaped anal groove (i), posterior margin of the dorsal scutum (ii), spiracular plate (iii) and (iv) genital pore are displayed for the four specimens.

The aim of this study was to evaluate the genetic and morphological identity of ticks, particularly $R$. sanguineus s.l. and to determine the presence of vector-borne pathogens in dogs, Canis lupus familiaris Linnaeus (Carnivora: Canidae), in Saudi Arabia. Both dogs and dromedary camels, Camelus dromedarius Linnaeus (Camelidae: Artiodactyla), were examined for ticks as they commonly share the same environment in Saudi Arabia. Tick morphological identity, including further enhancement using scanning electron microscopy (SEM), was coupled with molecular identity using genomic DNA (gDNA) isolation followed by amplification of fragments of the cytochrome c oxidase subunit I (cox1), 12S ribosomal DNA (rDNA) and 16S rDNA markers. In addition, gDNA isolated from blood samples of dogs was tested using various molecular assays including a multiplex tandem PCR (MT-PCR) panel and diagnostic PCR assays (Babesia gibsoni, Babesia vogeli, Mycoplasma haematoparvum, Mycoplasma haemocanis, Anaplasma platys, Hepatozoon canis and Ehrlichia canis).

\section{MATERIALS AND METHODS}

\section{Study sites and material collections}

Riyadh is a large province of central Saudi Arabia that covers an area of $404,000 \mathrm{~km}^{2}$, geographically positioned at latitude $24^{\circ} 42^{\prime} \mathrm{N}$ and longitude $46^{\circ} 43^{\prime} \mathrm{E}$. The climate is semiarid with very hot summers approaching $50^{\circ} \mathrm{C}$ and an average high temperature in July of $45^{\circ} \mathrm{C}$. The winters are cold with windy conditions at night. The overall climate is arid, receiving very little annual rainfall $(21.4 \mathrm{~mm})$ with relative humidity ranging from 10 to $47 \%$ throughout the year (General Authority of Meteorology \& Environmental Protection 2016).

The population of Riyadh is over six million people and the population of livestock such as camels, cattle, sheep and goats totals more than two million (General Authority for Statistics 2014). Culling of stray dogs is common in Saudi Arabia, with health authorities euthanising over 13,000 dogs between 2010 to 2015, while in 2016 the Riyadh municipality alone euthanised 3,486 stray dogs.

A total of 186 ticks of various developmental stages (20 nymphs, 166 adults) were collected from March to July 2017. All ticks from this study were collected from free-roaming dogs ( $n=73$ ) or dromedary camels $(n=113)$. Ticks from individual animals were stored in $70 \%$ ethanol upon collection.

The blood samples were collected between March and July 2016. A total of 53 stray dogs (19 male and 34 female), 15 from private veterinary clinics (stray dogs collected by health authorities for vaccinations and trap-neuter-release programmes) and 38 from locations within Riyadh, were taken to the 'Riyadh Municipality House' (animal holding facility) of the Environmental Health Department, Riyadh Municipality. Dogs of both sexes and various ages $(<1$ to $>5$ years old) were examined for haemopar- 
A (i)

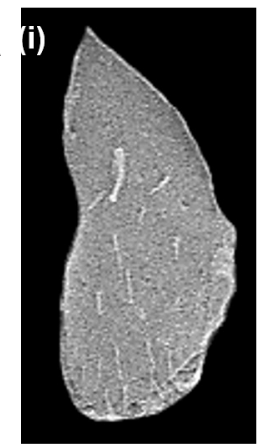

B

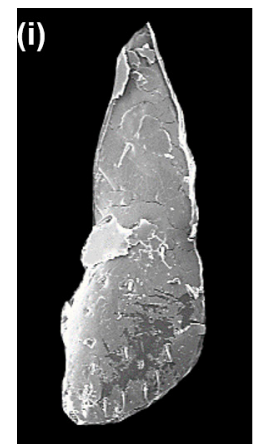

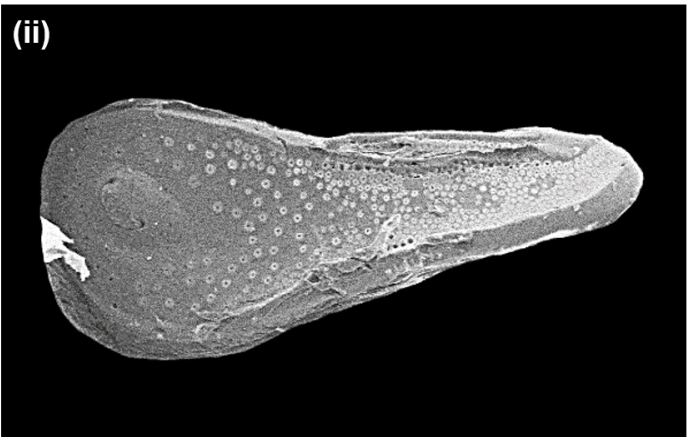

(ii)

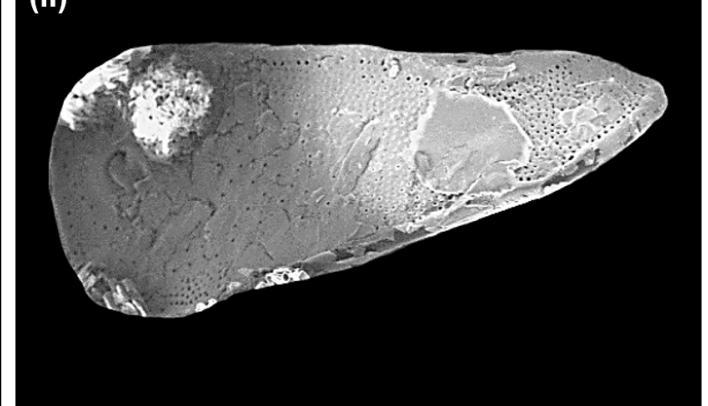

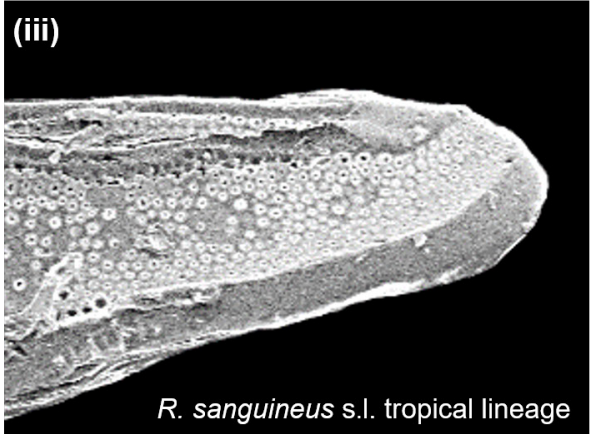

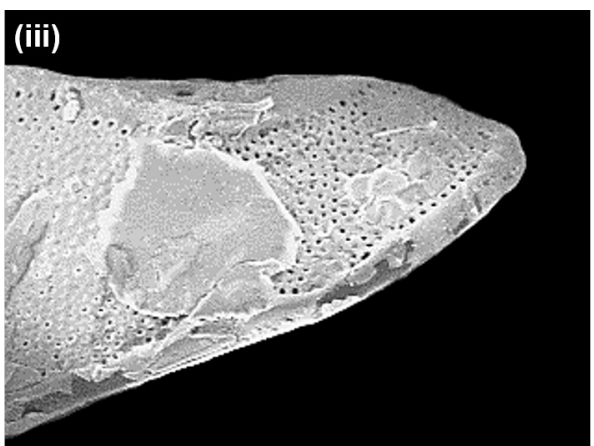

Fig. 2. Characteristics of male Rhipicephalus sanguineus s.l. tropical lineage (A) and Rhipicephalus turanicus (B) as seen with SEM. Rhipicephalus sanguineus s.l. tropical lineage from Von Berky Veterinary Services, Australia as part of a laboratory raised colony and Rhipicephalus turanicus (SC0146) from Riyadh, Saudi Arabia are shown. Adanal plates (i), spiracular plate (ii) and dorsal projection of spiracular plate (iii) are displayed for the two specimens.

asites. Blood samples were collected from each dog (2 to $5 \mathrm{ml})$ from the cephalic vein into vacutainers without anticoagulant (BD Vacutainer ${ }^{\circledR}$ Tube, Gribbles Veterinary Pathology, Clayton, Australia) and transported to the Parasitological Laboratory, Department of Biological Science, Faculty of Science and Humanities, Shaqra University for DNA extraction.

Tick collection and blood sampling for this study was approved by the Ethical and Human Research Committee, Shaqra University and complied with relevant guidelines for animal handling and welfare.

\section{Morphological identification and DNA isolation of ticks}

All ticks were identified morphologically at the Sydney School of Veterinary Science, University of Sydney using a stereo microscope (SMZ-2B, Nikon, Rhodes, Australia) with the aid of keys and guides (Hoogstraal 1956, Hoogstraal et al. 1981, Pegram et al. 1982a, Walker et al. 2005, Apanaskevich and Horak 2008, Apanaskevich et al. 2008, Apanaskevich and Horak 2009, Dantas-Torres et al. 2013) (Table 1). Identification to species level was not possible for four Amblyomma ticks and two Haemaphysalis ticks as the specimens were damaged.

Rhipicephalus sanguineus s.l. and Hyalomma spp. were halved using a no. 15 or no. 24 scalpel blade. One half of the tick tissue was used for total tick gDNA isolation in accordance with the ISOLATE II Genomic DNA Kit (Bioline, Eveleigh, Australia), with the following modifications: tick samples were digested in $180 \mu 1$ of lysis buffer, $25 \mu 1$ of proteinase $\mathrm{K}$ for $12-16$ hours at $56^{\circ} \mathrm{C}$ on a heat-block. The DNA isolation method was completed as per the kit instructions and total DNA was eluted into $80 \mu \mathrm{l}$ of elution buffer (Tris buffer, $\mathrm{pH}=8.5$, preheated to $70^{\circ} \mathrm{C}$ ).

For subsequent PCR and sequence analysis, we used gDNA from four $R$. sanguineus s.l. and 38 Hyalomma spp. DNA from $R$. sanguineus s.1. (SC0862, SC0863, SC0864, SC0867-1, SC08672, SC0867-3, SC0893-1) was excluded, because PCR amplification had repeatedly failed at all tested loci. DNA from Hyalomma dromedarii (SC0134, SC0137, SC0148) was excluded, because of incongruent phylogeny at cox $1,16 \mathrm{~S}$ rDNA and $12 \mathrm{~S}$ rDNA due to suspected amplification of pseudogenes at $12 \mathrm{~S}$ rDNA.

Amplification of the tick mitochondrial encoded cytochrome c oxidase subunit I (cox1), 12S ribosomal DNA (12S rDNA) and $16 \mathrm{~S}$ ribosomal DNA (16S rDNA) genes

A 604 nucleotide (nt) 5' fragment of the cytochrome $c$ oxidase subunit 1 (cox 1$)$ gene was amplified in a conventional PCR using forward primer S0725 (F1) (5'-TAC TCT ACT AAT CAT AAA GAC ATT GG-3') and reverse primer S0726 (R1) (5'-CCT CCT CCT GAA GGG TCA AAA AAT GA-3') (Kushimo 2013). A 336 nt 5 ' fragment of the $12 \mathrm{~S}$ ribosomal DNA (12S rDNA) gene was amplified in a conventional PCR using forward primer S0738 (T1B) (5'-AAA CTA GGA TTA GAT ACC CT-3') and reverse primer S0739 (T2A) (5'-AAT GAG AGC GAC GGG CGA TGT3') (Beati and Keirans 2001). A 276 nt 5' fragment of the $16 \mathrm{~S}$ ribosomal DNA (16S rDNA) gene was amplified in a conventional PCR using forward primer S0749 (5'-CTG CTC AAT GAT TTT TTA AAT TGC TGT GG-3') and reverse primer S0750 (5'-TTA CGC TGT TAT CCC TAG AG-3') (Black and Piesman 1994).

MyTaq $^{\text {TM }}$ Red Mix (Bioline, Rhodes, Australia) was used for cox $1,12 \mathrm{~S}$ rDNA and $16 \mathrm{~S}$ rDNA amplification in $30 \mu 1$ reactions using $2 \mu 1$ template gDNA. The PCR cycling conditions were as follows: $95^{\circ} \mathrm{C}$ for $1 \mathrm{~min}$ and 35 cycles of $95^{\circ} \mathrm{C}$ for $15 \mathrm{~s}, 55^{\circ} \mathrm{C}$ for $15 \mathrm{~s}$ and $72^{\circ} \mathrm{C}$ for $10 \mathrm{~s}$ followed by $72^{\circ} \mathrm{C}$ for $5 \mathrm{~min}$. All reactions contained a positive control and PCR grade water as a negative control. All conventional PCRs were conducted in an Applied Biosystems Veriti ${ }^{\mathrm{TM}}$ Thermal Cycler (Thermo Fisher Scientific, 

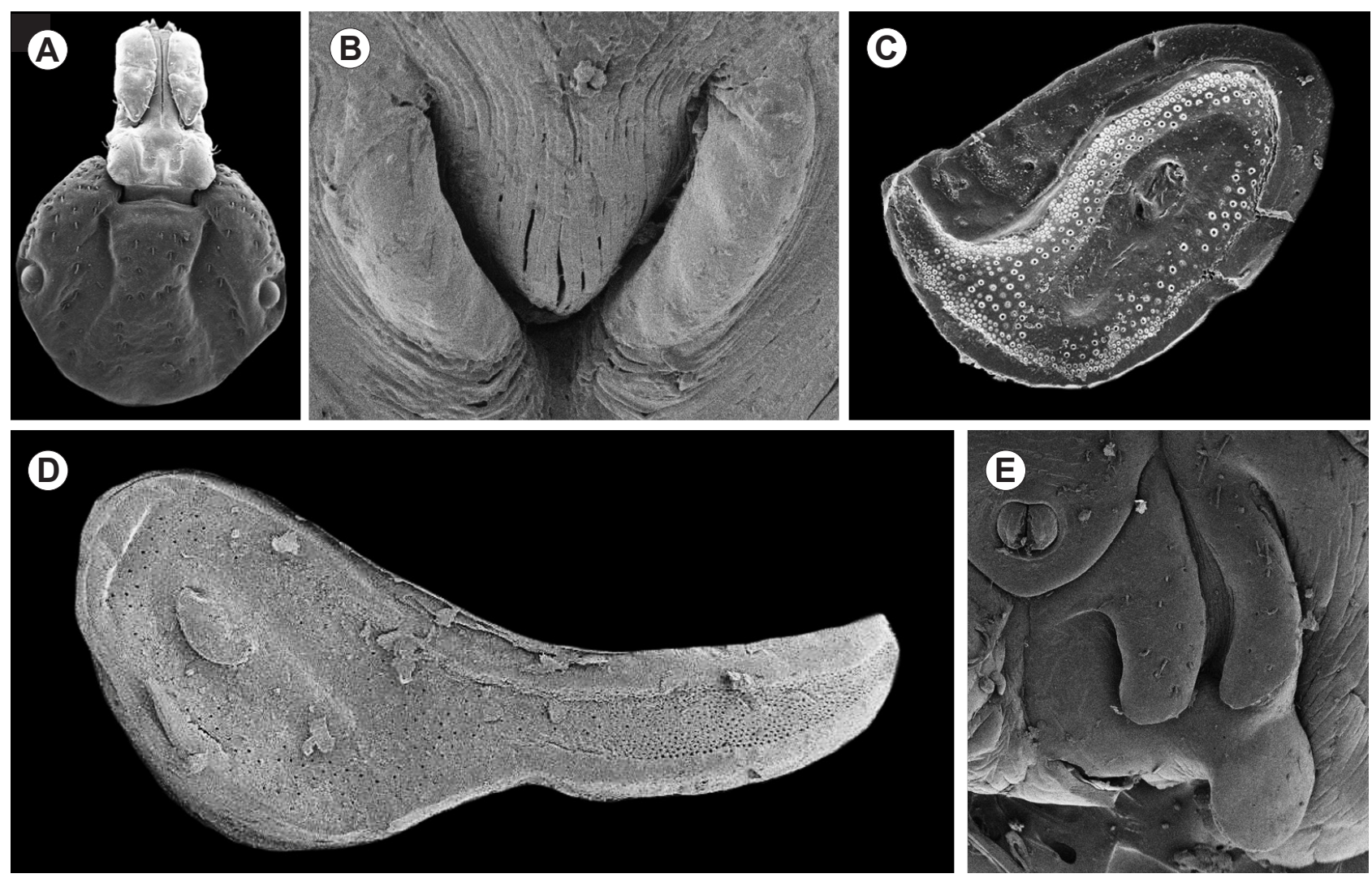

Fig. 3. Morphological characteristics of adult female and male Hyalomma dromedarii ticks from Riyadh, Saudi Arabia as seen with SEM. Key features of an adult female SC0116 (A-C) and an adult male SC0100 (D-E) are shown. Scutum and dorsal aspect of capitulum (A), narrow V-shaped genital pore (B), hooked / comma-shaped spiracular plate (C) are displayed for adult female Hyalomma dromedarii, SC0116. Spiracular plate (D) with long dorsal prolongation and narrow perforated section and (E), medially curved adanal and pronounced, large subanal shields are shown for adult male Hyalomma dromedarii, SC0100.

North Ryde, Australia) or a T100 TM Thermal Cycler (BioRad, Gladesville, Australia). PCR products were bi-directionally sequenced at Macrogen Ltd. (Seoul, South Korea).

Observation of key tick morphological features using a benchtop scanning electron microscope (SEM)

Key morphological features were excised from the ticks (SC0110, SC0116, SC0126-1, SC0127, SC0141, SC0146) using a clean no. 15 or 24 scalpel blade and were attached to $12.7 \mathrm{~mm}$ mounting SEM pin stubs (Ted Pella Inc., Redding, USA) with double sided carbon tape. They were then placed on a rotary planetary specimen stage in a K550X Sputter Coater unit (Quorum Technologies, Kent, UK) and coated in gold ( $\mathrm{Au}$ ) with the following parameters: current $25 \mathrm{~mA}$, time 2:00 mins and coating $15 \mathrm{~nm}$. Once coated, specimens were placed in a JEOL Neoscope, JCM-6000 (Nikon, Rhodes, Australia) for SEM observation.

\section{Tick DNA sequence analysis}

Sequences were assembled using CLC Main Workbench 6.8.1 (Qiagen, Vedbæk, Denmark). Phylogenetic analysis of DNA and the composition of the nucleotide sequences of species of Hyalomma Koch, 1844 and Rhipicephalus Koch, 1844 were determined using MEGA 7.0 (Kumar et al. 2016). Whole tick mitochondrial genome sequences from GenBank (NCBI) for $R$. sanguineus sensu Nava et al. 2018 (AF081829) and R. sanguineus s.l. tropical lineage (JX416325) were used to measure the proportional distance (p-distance) after trimming the sequences to the same nucleotide length. Molecular phylogenetic analyses were conducted for $R$. sanguineus s.l. at the $12 \mathrm{~S}$ rDNA, cox 1 and 16S rDNA loci and for Hyalomma spp. at the cox 1 locus. Phylogenetic comparison was made between available haplotypes on GenBank (NCBI) using MEGA 7.0 to determine the haplotypes within the populations (Kumar et al. 2016). The evolutionary history methods were inferred by MEGA 7.0 and were generated as the best fit DNA models (Tajima and Nei 1984, Rzhetsky and Nei 1992, Kumar et al. 2016). The evolutionary histories, evolutionary distances and evolutionary rate differences were inferred using the following methods: maximum likelihood (ML) method based on the Tamura-3 model and Gamma distribution was used to model the evolutionary rate differences among sites (four categories) (ML T92+G) and minimum evolution (ME) with Kimura-2 Parameters and Gamma distribution (four categories) (ME K2P $+\mathrm{G}$ ). Test of phylogeny was estimated using Bootstrap method (1000 replications). The bootstrap confidence intervals (\%) have been grouped as follows: ML T92+G / ME K2P $+\mathrm{G}$ and values $<50 \%$ have been hidden on the phylogenetic trees.

\section{Canine blood DNA extraction}

Total gDNA was isolated using the DNeasy Blood and Tissue kit (Qiagen, Denmark) and eluted in 50-100 $\mu$ l of elution buffer as per the manufacturer's instruction. An aliquot of 50-100 $\mu \mathrm{l}$ of gDNA from each of the samples was stored at $-80^{\circ} \mathrm{C}$ prior to being sent to the Veterinary Pathology Diagnostic Services (VPDS), 


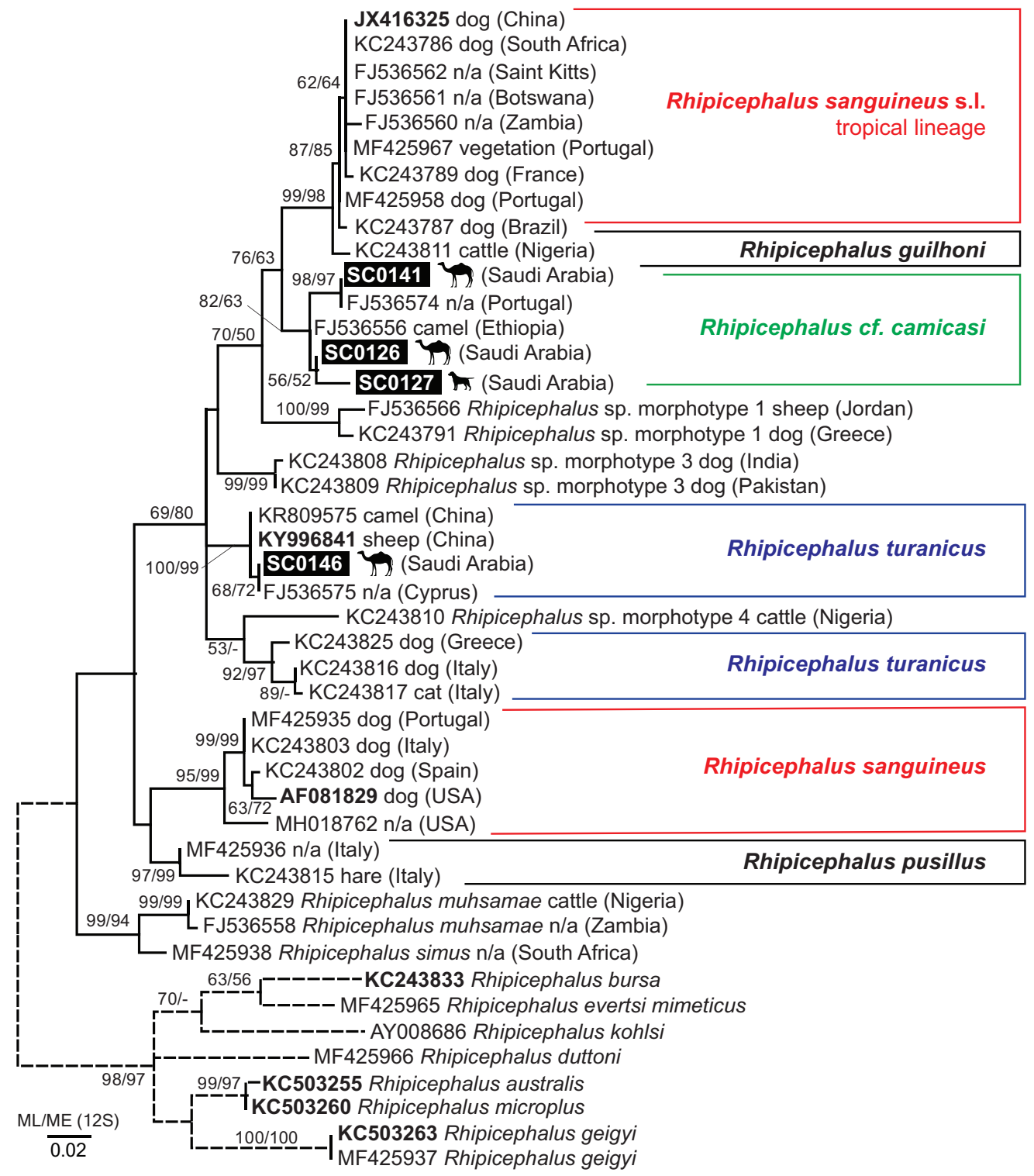

Fig. 4. Molecular phylogenetic analysis of Rhipicephalus sanguineus (Latreille, 1806) sensu lato at the 12S ribosomal DNA locus. The phylogenetic tree has been inferred using the ML method and the bootstrap confidence intervals (1000 replicates) have been displayed on the branch nodes in the following order: ML T92+G / ME K2P+G. Bootstrap values $<50 \%$ have been hidden. Accession numbers of similar reference sequences have been obtained from Genbank (NCBI) and host species and country of collection has been included, if available. No information provided for host species was indicated with ' $n / a$ '. Country of collection is shown in parentheses. Whole mitochondrial genomes are indicated with bold text.

Sydney School of Veterinary Science, University of Sydney for PCR analysis. At VPDS, gDNA was stored at $-20^{\circ} \mathrm{C}$ for up to one month prior to molecular diagnostics.

Commercial real-time quantitative PCR assay: Multiplexed Tandem PCR (MT-PCR) Canine Anaemia Panel

A commercial diagnostic MT-PCR was performed using the 7plex Canine Anaemia Panel (R910738, AusDiagnostics Pty. Ltd, Australia) as per the manufacturer's instructions. The MT-PCR assay is a two-step nested PCR assay simultaneously targeting apicomplexans Babesia gibsoni, Babesia vogeli and bacteria $M y-$ coplasma haematoparvum, Mycoplasma haemocanis, Anaplasma platys and Hepatozoon canis and was run on the Easy-Plex ${ }^{\mathrm{TM}}$ platform (AusDiagnostics, Mascot, Australia). The assay was run in duplicate using undiluted samples $(n=53)$ and 30 samples using diluted template DNA $(1: 10)$. Each run included controls to detect PCR inhibition and sample adequacy control (ANONO) as per the manufacturer's protocol.

In-house conventional PCR assays: Babesia spp., Mycoplasma spp., Anaplasma platys, Hepatozoon canis and Ehrlichia canis

Conventional non-nested PCR assays targeting H. canis (HEP-F/ HEP-R) (Harrus et al. 2011), A. platys (Platys/EHR16SR) (Harrus et al. 2011), Mycoplasma spp. (HBT-F/HBT-R) (Marie et al. 2009, Barker et al. 2012), E. canis (EHR16SD/ EHR16SR) (Barker et al. 2012, Nazari et al. 2013) and Babesia spp. (Babgen-F/Babgen-R) (Oliveira et al. 2009, Santos et al. 2009, Barker et al. 2012) were applied. In addition, a conventional nested PCR targeting Babesia spp. (BTF1/BTR1 \& BTF2/BTR2) was performed. 


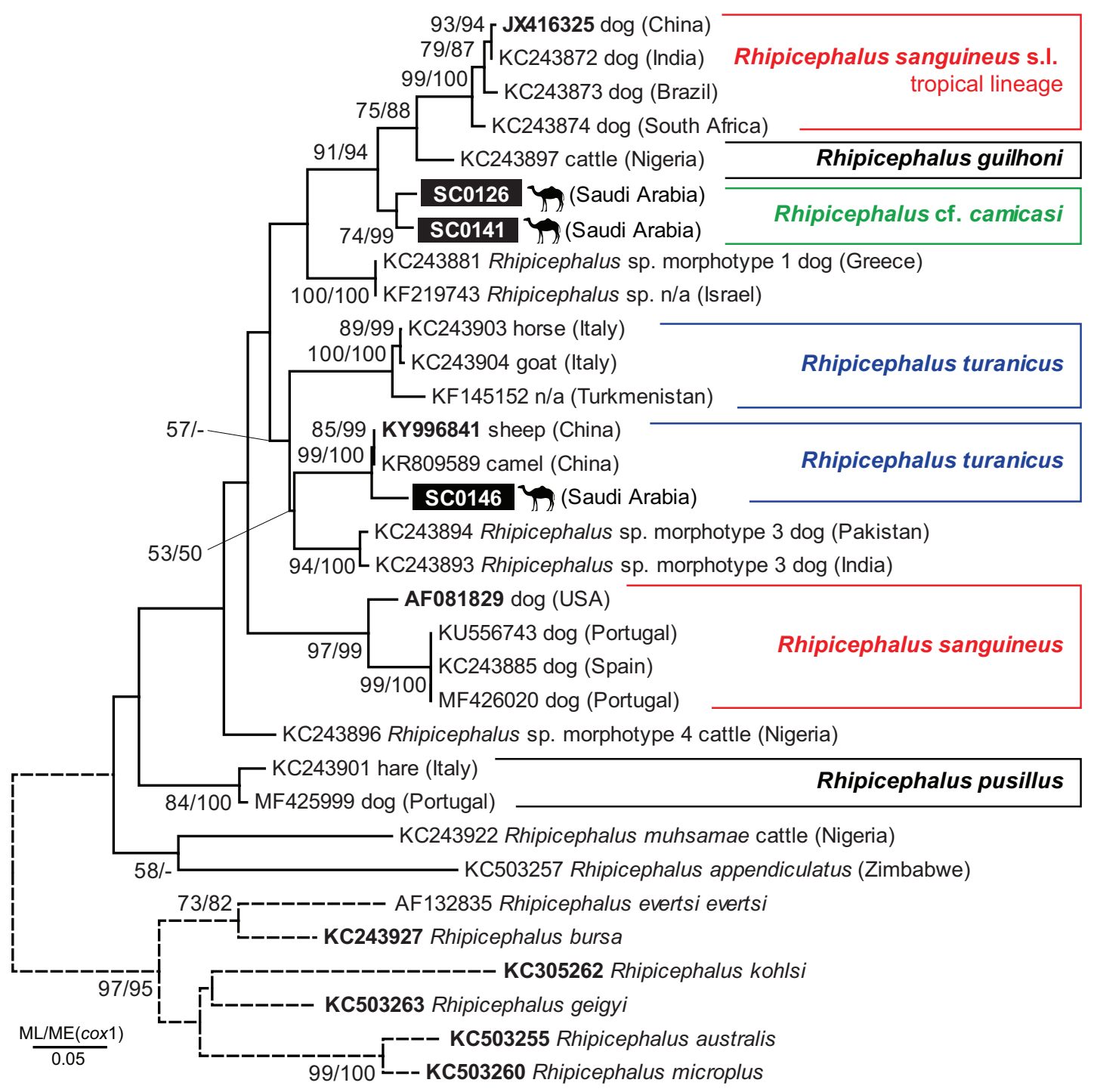

Fig. 5. Molecular phylogenetic analysis of Rhipicephalus sanguineus (Latreille, 1806) sensu lato at the cytochrome c oxidase subunit I locus. The phylogenetic tree has been inferred using the ML method and the bootstrap confidence intervals (1000 replicates) have been displayed on the branch nodes in the following order: $\mathrm{ML}$ T92 $+\mathrm{G} / \mathrm{ME} \mathrm{K} 2 \mathrm{P}+\mathrm{G}$. Bootstrap values $<50 \%$ have been hidden. Accession numbers of similar reference sequences have been obtained from Genbank (NCBI) and host species and country of collection has been included, if available. No information provided for host species was indicated with ' $\mathrm{n} / \mathrm{a}$ '. Country of collection is shown in parentheses. Whole mitochondrial genomes are indicated with bold text.

All PCR reactions were run using MyTaq ${ }^{\mathrm{TM}}$ RedMix (Bioline, Rhodes, Australia) in an Applied Biosystems Veriti ${ }^{\mathrm{TM}}$ Thermal Cycler (Thermo Fisher Scientific, North Ryde, Australia). Primers were included at a final concentration of $400 \mathrm{~nm} / \mu 1$ and 2 $\mu 1$ of template DNA was used per reaction. All non-nested PCR were run using the following cycling conditions: $95^{\circ} \mathrm{C}$ for $1 \mathrm{~min}$ and 35 cycles of $95^{\circ} \mathrm{C}$ for $15 \mathrm{~s}, 50^{\circ} \mathrm{C}$ for $15 \mathrm{~s}$ and $72^{\circ} \mathrm{C}$ for $10 \mathrm{~s}$ followed by $72^{\circ} \mathrm{C}$ for 5 min. PCR reactions with Babgen-F/Babgen-R primers were run with an annealing temperature of $55^{\circ} \mathrm{C}$ and all other conditions as previously described.

The first round of the nested PCR was run using the following cycling conditions: $95^{\circ} \mathrm{C}$ for $1 \mathrm{~min}$ and 35 cycles of $95^{\circ} \mathrm{C}$ for 15 s, $55^{\circ} \mathrm{C}$ for $15 \mathrm{~s}$ and $72^{\circ} \mathrm{C}$ for $10 \mathrm{~s}$ followed by $72^{\circ} \mathrm{C}$ for $5 \mathrm{~min}$. The second round of the nested PCR was run using a $60^{\circ} \mathrm{C}$ annealing temperature with all other conditions as described for the first round. All assays included a negative and positive control. All PCR products were separated by electrophoresis in $2 \%$ agarose gel stained with GelRed ${ }^{\mathrm{TM}}$ (Biotium, Fremont, USA) and visualised using UV light. Discrete bands of expected size were submitted for bidirectional sequencing using amplification primers (Macrogen Ltd., Seoul, South Korea). Sequences were assembled and compared to closely related sequences using CLC Main Workbench 6.9.1. (Qiagen, Vedbæk, Denmark).

\section{Statistical analysis}

A statistical analysis to determine freedom from disease/pathogen was conducted using FreeCalc2 calculator (http://epitools.ausvet.com.au) (Sergeant 2017). The analysis assumed a theoretical test sensitivity and specificity of $100 \%$ and a population size of 3,500, based on the number of dogs euthanised in Saudi Arabia in 2016.

\section{Availability of data and material}

Tick vouchers are deposited in the Australian National Insect Collection (CSIRO, Canberra, Australia). Nucleotide se- 


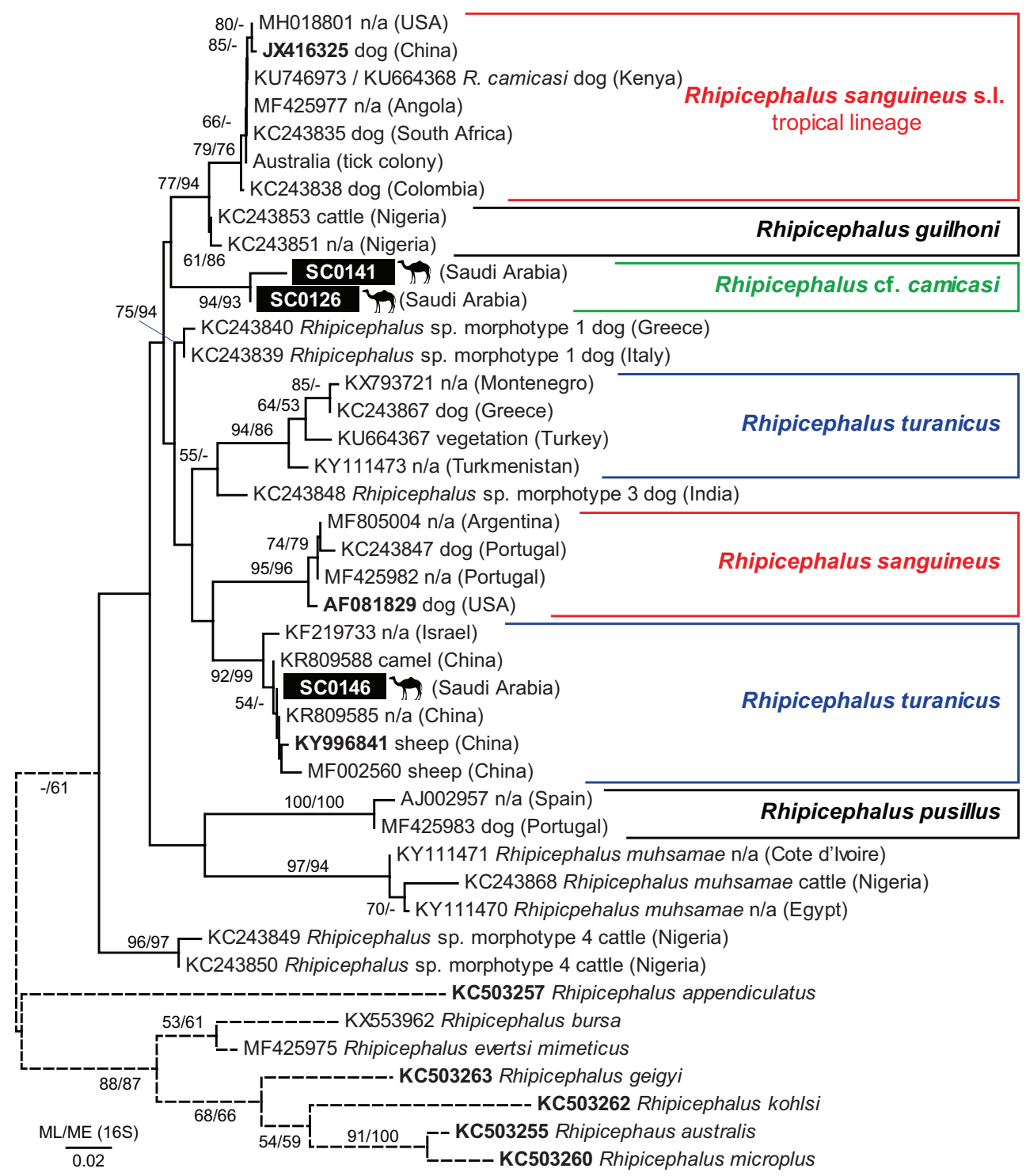

Fig. 6. Molecular phylogenetic analysis of Rhipicephalus sanguineus (Latreille, 1806) sensu lato at the 16S ribosomal DNA locus. The phylogenetic tree has been inferred using the ML method and the bootstrap confidence intervals (1000 replicates) have been displayed on the branch nodes in the following order: ML T92+G / ME K2P+G. Bootstrap values $<50 \%$ have been hidden. Accession numbers of similar reference sequences have been obtained from Genbank (NCBI) and host species and country of collection has been included, if available. No information provided for host species was indicated with ' $\mathrm{n} / \mathrm{a}$ '. Country of collection is shown in parentheses. Whole mitochondrial genomes are indicated with bold text.

quence data from this study are available in the GenBank database (National Center for Biotechnology Information, NCBI) database under accession numbers MH094440-MH094483 (cox1), MH094484-MH094508, MK757703-MK757707 (12S rDNA) and MH701863-MH701865, MK737502-MK737509 (16S rDNA). A summary of the ticks used in this study, sequence alignments and raw SEM images are available at LabArchives [https://doi.org/10.25833/9f0h-bb16]. A detailed summary of diagnostic assay outcomes is given in Supplementary Table 1.

\section{RESULTS}

Rhipicephalus sanguineus s.l. and Hyalomma spp. from dogs and dromedary camels

A total of 186 ticks were collected in Riyadh, Saudi Arabia from a total of 65 free roaming dogs (73 ticks) and
84 dromedary camels (113 ticks) (Table 1). Morphological analysis confirmed 5.9\% (11/186) ticks were $R$. sanguineus s.1., collected from three dogs (ticks: SC0127, SC0867-1 to SC0867-3, SC0893-1) and six camels (ticks: SC0126-1, SC0141, SC0146, SC0862, SC0863, SC0864). The most commonly detected ticks were Hyalomma spp. (93.5\%, 174/186), collected from 58 dogs (63 ticks) and 77 camels (106 ticks) (Table 1). Most of the ticks found were identified as the camel tick, Hyalomma dromedarii $(n=162)$ and six other hyalommine ticks - one Hyalomma impeltatum Schulze et Schlottke, 1930 (SC0107), two Hyalomma excavatum Koch, 1844 (SC0128, SC0129), one Hyalomma turanicum Pomerantsev, 1946 (SC0133), one Hyalomma arabica Pegram, Hoogstraal et Wassef, 1982 (SC0135), one Hyalomma rufipes Koch, 1844 (SC0136) and one Hyalomma anatolicum Koch, 1844 (SC0139). 


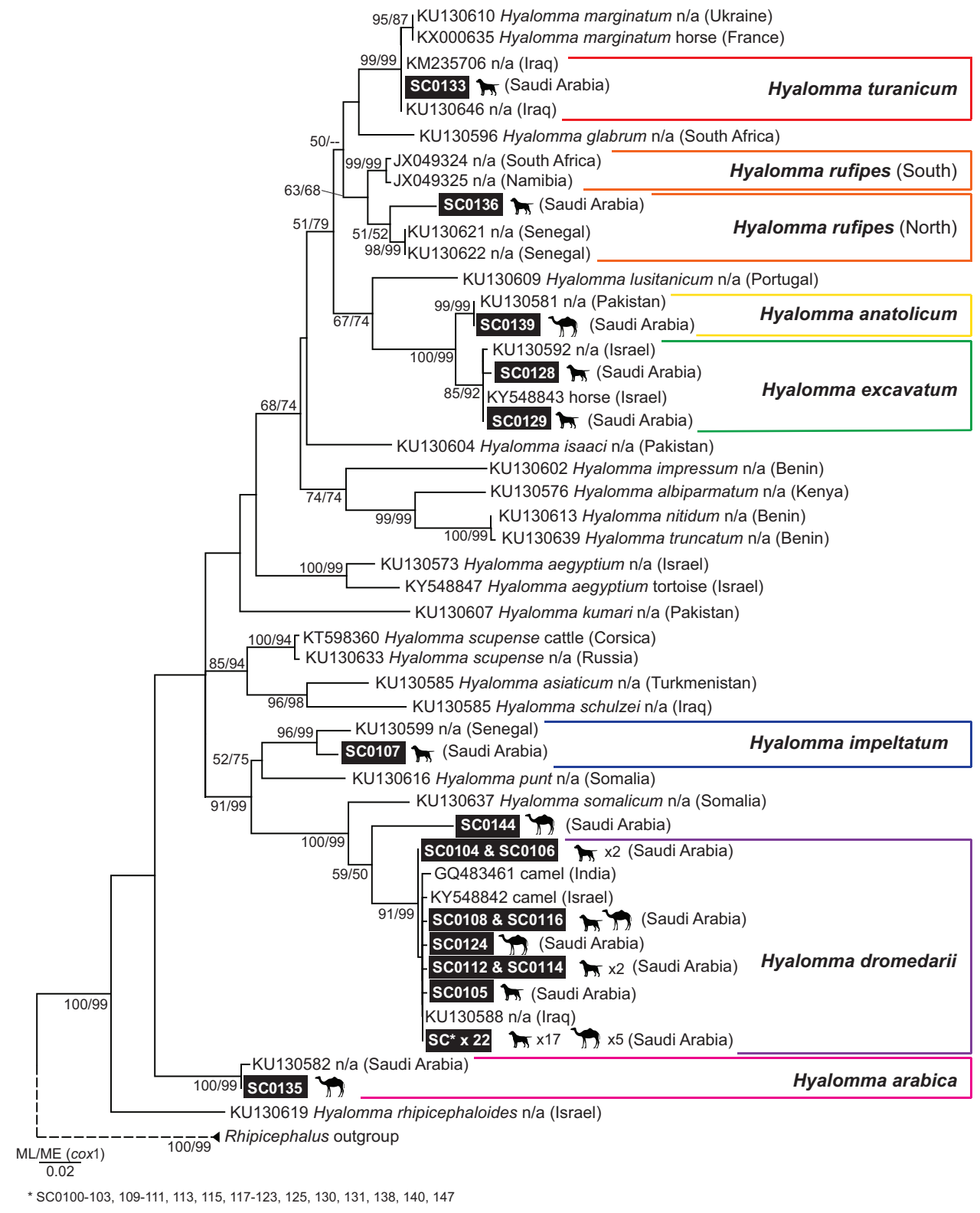

Fig. 7. Molecular phylogenetic analysis of Hyalomma (Koch, 1844) species at the cytochrome c oxidase subunit I locus. The phylogenetic tree has been inferred using the ML method and the bootstrap confidence intervals (1000 replicates) have been displayed on the branch nodes in the following order: $\mathrm{ML} \mathrm{T} 92+\mathrm{G} / \mathrm{ME} \mathrm{K} 2 \mathrm{P}+\mathrm{G}$. Bootstrap values $<50 \%$ have been hidden. Accession numbers of similar reference sequences have been obtained from Genbank (NCBI) and host species and country of collection has been included, if available. No information provided for host species was indicated with ' $\mathrm{n} / \mathrm{a}$ '. Country of collection is shown in parentheses. Whole mitochondrial genomes are indicated with bold text.

To complement morphological identification of R. sanguineus s.l., we performed SEM for the female ticks (SC0126-1, SC0127, SC0141; Fig. 1) and the male tick (SC0146; Fig. 2). Female R. sanguineus s.l. matched the characteristics including the posterior margin of the dorsal scutum and spiracular plate for $R$. sanguineus s.l. tropical lineage sensu Dantas-Torres et al. (2013) (Fig. 1). The genital pore area, specifically the shape of the genital aperture posterior lips, was a narrow U shape (Fig. 1). The genital area of SC0126-1 was too damaged to be unambiguously identified. For the male tick (SC0146) the relevant distinctive characteristics including the shape of the adanal plate and spiracular plate as well as the dorsal projection of the spiracular plate resembled Rhipicephalus sp. II sensu Dan-
tas-Torres et al. (2013) (Fig. 2). The SEM of an adult female $H$. dromedarii (SC0116) and an adult male H. dromedarii (SC0100) displayed characteristic morphological features consistent with the reference description of $H$. dromedarii (Hoogstraal 1956, Apanaskevich et al. 2008) (Fig. 3).

\section{Molecular identification of Rhipicephalus sanguineus s.l.: Rhipicephalus cf. camicasi and Rhipicephalus turanicus}

For molecular identification of $R$. sanguineus s.l., we characterised ticks at cox $1,12 \mathrm{~S}$ rDNA and 16S rDNA (Figs. 4-6). Three cox1 (604 nt; SC0126-1, SC0141, SC0146), four 12S rDNA (336 nt; SC0126-1, SC0127, SC0141, SC0146) and three 16S rDNA (276 nt; SC0126-1, SC0141, SC0146) fragments were sequenced. 
Table 1. Ticks found on free-roaming dogs and dromedary camels from Saudi Arabia

\begin{tabular}{|c|c|c|c|c|c|c|c|c|}
\hline \multirow{3}{*}{ Species identity } & \multicolumn{4}{|c|}{ Dog (Canis familiaris), $n=65$} & \multicolumn{4}{|c|}{ Camel (Camelus dromedarius), $n=84$} \\
\hline & \multirow{2}{*}{$\begin{array}{l}\text { Number of } \\
\text { dogs sampled }\end{array}$} & \multicolumn{3}{|c|}{$\begin{array}{l}\text { Number of ticks } \\
\text { (total } n=73 \text { ) }\end{array}$} & \multirow{2}{*}{$\begin{array}{l}\text { Number } \\
\text { of camels } \\
\text { sampled }\end{array}$} & \multicolumn{3}{|c|}{$\begin{array}{l}\text { Number of ticks } \\
\text { (total } n=113 \text { ) }\end{array}$} \\
\hline & & Adult $\hat{O}$ & Adult + & Nymph & & Adult $\widehat{\partial}$ & Adult ㅇ & Nymph \\
\hline $\begin{array}{l}\text { Rhipicephalus cf. camicasi } \\
\text { Morel, Mouchet et Rodhain, } 1976\end{array}$ & 1 & & 1 & & 2 & & 1 & 1 \\
\hline $\begin{array}{l}\text { Rhipicephalus turanicus } \\
\text { Pomerantsev, } 1936\end{array}$ & 0 & & & & 1 & & & 1 \\
\hline $\begin{array}{l}\text { Rhipicephalus sanguineus } \\
\text { (Latreille, 1806) s.l. }\end{array}$ & 2 & & 3 & 1 & 3 & 2 & 1 & \\
\hline $\begin{array}{l}\text { Hyalomma dromedarii } \\
\text { Koch, } 1844\end{array}$ & 53 & 30 & 18 & 11 & 74 & 55 & 43 & 5 \\
\hline $\begin{array}{l}\text { Hyalomma cf. dromedarii } \\
\text { Koch, } 1844\end{array}$ & 0 & & & & 1 & 1 & & \\
\hline $\begin{array}{l}\text { Hyalomma excavatum } \\
\text { Koch, } 1844\end{array}$ & 2 & & 2 & & 0 & & & \\
\hline $\begin{array}{l}\text { Hyalomma turanicum } \\
\text { Pomerantsev, } 1946\end{array}$ & 1 & 1 & & & 0 & & & \\
\hline $\begin{array}{l}\text { Hyalomma anatolicum } \\
\text { Koch, } 1844\end{array}$ & 0 & & & & 1 & & 1 & \\
\hline $\begin{array}{l}\text { Hyalomma rufipes } \\
\text { Koch, } 1844\end{array}$ & 1 & & & & 0 & & & \\
\hline $\begin{array}{l}\text { Hyalomma impeltatum } \\
\text { Schulze et Schlottke, } 1930\end{array}$ & 1 & 1 & & & 0 & & & \\
\hline $\begin{array}{l}\text { Hyalomma arabica } \\
\text { Pegram, Hoogstraal et Wassef, } 1982\end{array}$ & 0 & & & & 1 & & & 1 \\
\hline Amblyomma spp. & 3 & 1 & 2 & & 1 & & 1 & \\
\hline Haemaphysalis spp. & 1 & & 2 & & 0 & & & \\
\hline
\end{tabular}

At all three mtDNA markers, female ticks (SC0126-1, SC0127, SC0141) formed a sister group to the $R$. sanguineus s.l. tropical lineage and Rhipicephalus guilhoni Morel et Vassiliades, 1963 (Figs. 4-6). The specimens are tentatively identified as Rhipicephalus cf. camicasi Morel, Mouchet et Rodhain, 1976. At 12S rDNA the sequences (SC0126-1, SC0127, SC0141) were monophyletic with $R$. camicasi (FJ536556) with bootstrap support of $82 \%$ (maximum likelihood) and 63\% (minimum evolution) (Fig. 4). The specimen $R$. camicasi (FJ536556) has a voucher USNTC-RML 107410 [U.S. National Tick Collection] collected from a camel (Camelus sp.) in Ethiopia, a type locality for $R$. camicasi. At the cox 1 locus, specimens SC0126-1 and SC0141 formed a highly supported clade to the $R$. sanguineus s.l. tropical lineage and $R$. guilho$n i$ with $91 \%$ (maximum likelihood) and 99\% (minimum evolution) bootstrap support (Fig. 5). At the $16 \mathrm{~S}$ rDNA locus, SC0126-1 and SC0141 did not form a monophyletic ( $<50 \%$ bootstrap) group with any of the recognised groups (Fig. 6). The cox1 (604 nt), 16S rDNA (274 nt) and 12S rDNA (335 nt) p-distance from $R$. sanguineus (AF081829) was $9.9 \%, 6.6-7.3 \%$ and $8.1-8.7 \%$ and p-distance from $R$. sanguineus s.1. tropical lineage (JX416325) was 7\%, $5.4-6.2 \%$ and $3.6-4.2 \%$, respectively.

The male tick (SC0146) morphologically resembling Rhipicephalus sp. II sensu Dantas-Torres et al. (2013) was monophyletic at cox $1,16 \mathrm{~S}$ rDNA and $12 \mathrm{~S}$ rDNA with what is recognised as $R$. turanicus within one of the two $R$. turanicus clades (Figs. 4-6). The specimen is determined to be $R$. turanicus. The cox 1 (604 nt), 16S rDNA (274 nt) and $12 \mathrm{~S}$ rDNA (335 nt) p-distance from $R$. sanguineus (AF081829) was $10.8 \%, 6.2 \%$ and $7.2 \%$ and p-distance from the $R$. sanguineus s.l. tropical lineage (JX416325) was and $9.4 \%, 6.5 \%$ and $5.9 \%$, respectively.

\section{Molecular identification of Hyalomma spp.}

The molecular characterisation of Hyalomma spp. confirmed the presence of $H$. dromedarii, $H$. excavatum, $H$. turanicum, $H$. anatolicum, $H$. rufipes, $H$. impeltatum and H. arabica at cox $1,12 \mathrm{~S}$ rDNA and 16S rDNA. All three genes were obtained from four $H$. dromedarii (SC0104, SC0106, SC0110, SC0116; from two dogs and two camels), two H. excavatum (SC0128, SC0129 from two dogs), one H. turanicum (SC0133 from dog) and one H. anatolicum (SC0139 from camel).

For $38(22 \%, 38 / 174)$ Hyalomma spp. ticks we obtained cox 1 sequences (Fig. 7). Using phylogenetic analysis at cox 1 , all but one sequence (H. dromedarii, SC0144) formed a monophyletic group with the reference sequences for $H$. dromedarii ( $n=30$, Fig. 7 ), H. excavatum (SC0128 and SC0129), H. turanicum (SC0133), H. anatolicum (SC0139), H. rufipes (SC0136), H. impeltatum (SC0107) and $H$. arabica (SC0135) from 28 dogs and nine camels (Fig. 7)

The sequence of SC0144 at cox 1 formed a distinct sister clade to $H$. dromedarii despite the unambiguous morphological identification of the voucher as $H$. dromedarii; the cox 1 sequence is referred as $H$. cf. dromedarii. Additional $12 \mathrm{~S}$ rDNA $(n=21)$ and $16 \mathrm{~S}$ rDNA $(n=8)$ were obtained to complement the cox 1 molecular identity. 


\section{Application of MT-PCR canine panel to detect canine vector borne disease agents}

In a complementary study, 53 dog blood samples were successfully processed in duplicate using the EasyPlex commercial diagnostic system to evaluate the presence of vector-borne pathogens in Saudi Arabia. The assay demonstrated an absence of PCR inhibition in 94\% (50/53) and $100 \%(53 / 53)$ in the duplicate MT-PCR. Similarly, 93\% $(28 / 30)$ of the diluted $(1: 10)$ samples showed an absence of PCR inhibition and adequate mammalian DNA (Supplementary Table 1). The internal controls in the MT-PCR assay showed that the dog blood DNA samples contained adequate mammalian DNA (ANONO).

The duplicate MT-PCR assay results demonstrated that most samples were free from specific pathogen DNA $(63 \%, 33 / 53)$ (Supplementary Table 1). Those that showed positive results in the MT-PCR assay exhibited low copy numbers of target DNA. As a result they were only suspected of being positive for the respective pathogen DNA, because the PCR results were impossible to differentiate from background fluorescence on inspection of the melt curve data (data not shown). One sample was suspected positive for DNA of Babesia vogeli $(2 \%, 1 / 53)$ with a calculated copy number of 43 reported. Three samples $(9 \%$, 3/53) were suspected positive for Mycoplasma haemocanis with copy numbers 29-56. Seventeen samples (32\%, 17/53) were suspected positive for Mycoplasma haematoparvum with copy numbers 20-101.

None of the samples were positive for DNA from Babesia gibsoni or Anaplasma platys. When diluted (1:10) none of the blood samples gave positive results. The suspected positive MT-PCR amplicon samples did not yield DNA sequences when submitted for DNA sequencing. To validate the MT-PCR results, we used previously described conventional PCR assays. None of the PCR assays were positive for the presence of DNA from A. platys, Ehrlichia canis, H. canis, Mycoplasma spp. or Babesia spp. (Supplementary Table 1). Therefore, we considered the previous MT-PCR suspected positive results to be false positives.

The above assays demonstrated absence of DNA for A. platys, E. canis, Hepatozoon canis, Mycoplasma spp. and Babesia spp. Zero in 53 samples from a total sample size of 3,500 is sufficient to confirm that the presence of the pathogen does not exceed $5.7 \%$. To demonstrate $2.5 \%$ and $0.5 \%$ prevalence of the pathogen, we would have to test 1,001 and 2,745 samples, respectively.

\section{DISCUSSION}

This study confirms the presence of Rhipicephalus sanguineus s.l., notably Rhipicephalus cf. camicasi on dogs and camels and Rhipicephalus turanicus on camels in Riyadh, Saudi Arabia and in the central Arabian Peninsula (Pegram et al. 1982b, 1987). Largely opportunistic in nature, $R$. turanicus typically parasitises cattle, sheep and dogs, but has been known to parasitise camels (Walker et al. 2005). Similarly, $R$. camicasi preferentially parasitises cattle, sheep, goats and camels, but it is infrequently reported on dogs (Pegram et al. 1987, Walker et al. 2005, Hekimoğlu et al. 2016). The low numbers of $R$. sanguineus s.1. $(5.6 \%, 11 / 186)$ found supports our pilot study on the reported low prevalence of canine vector-borne diseases in Saudi Arabia. While the principal host of Hyalomma dromedarii is commonly dromedary camels, we have demonstrated the presence of $H$. dromedarii on free-roaming dogs which share the same environment as the camels (Hoogstraal et al. 1981, Elghali and Hassan 2010, Abdel-Shafy et al. 2012). To our knowledge, this is the first study that confirms the frequent presence of $H$. dromedarii on dogs.

The phylogeny of the Saudi Arabian $R$. cf. camicasi isolates demonstrates a clear genetic distinction from $R$. sanguineus s.l. tropical lineage at three mitochondrial loci (cox $1,12 \mathrm{~S}$ rDNA, 16S rDNA). Using the available morphological criteria, it is difficult to unambiguously differentiate $R$. camicasi sensu Morel et al. (1976) from ' $R$. sanguineus s.l. (= tropical species)' sensu Dantas-Torres et al. (2013) (see Morel et al. 1976, Dantas-Torres et al. 2013). The sinuous shape of the posterior margin of the female scutum and the narrow tails of the spiracular plate of $R$. camicasi sensu Morel et al. (1976) match those observed on our material from Saudi Arabia, yet they largely overlap those outlined for ' $R$. sanguineus s.l. (= tropical species)' sensu Dantas-Torres et al. (2013) (see Morel et al. 1976, Dantas-Torres et al. 2013).

Rhipicephalus camicasi requires a revision, including the original material and new material collected from the type locality, to confirm its morphological and molecular identity. Conservatively, we propose to call the Saudi Arabian ticks $R$. cf. camicasi characterised both morphologically and genetically. At $12 \mathrm{~S}$ rDNA, our sequences (MH094505-MH094507) formed a clade with two unpublished sequences, one $R$. camicasi from a camel in Ethiopia (FJ536556) and one Rhipicephalus sp. with unknown host from Portugal (FJ536574).

Interestingly, the original reference type for $R$. camicasi was recovered from Ethiopia on a camel (Morel et al. 1976). At the $16 \mathrm{~S}$ rDNA marker, there is a $R$. camicasi sequence (KU664368) recovered from a dog in northern Kenya, but the detailed morphology was not described. This sequence (KU664368), however, falls unambiguously into the $R$. sanguineus s.1. tropical lineage, distinct from what we recognise as $R$. cf. camicasi.

Molecular identity studies of $R$. sanguineus s.l. are typically concentrated at two mtDNA markers, $12 \mathrm{~S}$ rDNA and 16S rDNA (Levin et al. 2012, Nava et al. 2012, Hekimoğlu et al. 2016, Chitimia-Dobler et al. 2017, Dantas-Torres et al. 2017). While it is commonly used for DNA barcoding for Metazoa (Hebert et al. 2003), cox1 is less frequently used in tick diversity studies, owing to the fact that there have been observed amplification issues (Lv et al. 2014, Low et al. 2015, Dantas-Torres et al. 2017). We noted a low amplification success rate for $R$. sanguineus $(27 \%, 3 / 11)$ at the cox 1 marker using unpublished primers (Kushimo 2013). It would be advisable to consider alternative cox 1 primers that have demonstrated good amplification success rate for brown dog ticks (Low et al. 2015, Low and Prakash 2018). Compared to the amplified regions of $12 \mathrm{~S}$ rDNA and $16 \mathrm{~S}$ rDNA, the cox 1 region is longer and it translates into protein sequences, which reduces the alignment am- 
biguity, including misalignment and sequencing errors. As longer regions are more robust in species delineation, the use of the cox 1 marker and mitochondrial genomes are imperative in delimiting cryptic species (Hebert et al. 2004, Burger et al. 2014).

Our survey demonstrated the presence of five species of the genus Hyalomma on dogs, including $H$. dromedar$i i, H$. turanicum, $H$. rufipes, $H$. excavatum and $H$. impeltatum, which was previously molecularly characterised (Sands et al. 2017). We have shown that H. dromedarii is the most common tick parasitising dogs in the region. The principal host species are camels, but $H$. dromedarii is known to parasitise other ungulates (Kaiser and Hoogstraal 1963, 1964, Hoogstraal et al. 1981, Apanaskevich and Horak 2010, Elghali and Hassan 2010). Domestic and wild ungulates, especially cattle, are frequently reported as the common host species for $H$. rufipes, $H$. turanicum and $H$. impeltatum. They have also been known to parasitise humans and $H$. excavatum has been known to parasitise dogs (Hoogstraal et al. 1981, Estrada-Peña et al. 2017).

Ticks of genus the Hyalomma have preferred hosts but tend to be generalist ticks and are highly adapted to living in harsh, arid desert environments and are commonly found on camels and cattle (Hoogstraal et al. 1981, Pegram et al. 1982a, b, Estrada-Peña et al. 2017). Due to the largely opportunistic nature of species of Hyalomma, they are likely opportunistic parasites of free-roaming dogs in the area, considering they co-exist in the same habitat as camels.

No canine vector-borne pathogens, including Anaplasma platys, Ehrlichia canis, Hepatozoon canis, Mycoplasma spp. and Babesia spp., were detected in a pilot study based on 53 dogs blood samples. Low prevalence $<5 \%$ is supported by the low prevalence of $R$. sanguineus s.l. parasitising dogs in Riyadh, Saudi Arabia and absence of the traditional vectors such as the $R$. sanguineus s.l. tropical lineage and temperate lineage (Seneviratna et al. 1973, Baneth et al. 2001, Brown et al. 2001, Hii et al. 2015).

The multiplexed assay (MT-PCR) outcome was verified using pathogen-specific assays that detect and identify the target vector-borne pathogens (Harrus et al. 2011, Otranto et al. 2011, Barker et al. 2012, Nguyen et al. 2016, Šlapeta and Šlapeta 2016). The implementation of internal controls in the MT-PCR assay enables direct confirmation of adequacy and inhibition. When fully validated, MT-PCR assays are sensitive to low copy numbers (Stanley and Szewczuk 2005).

In this study, the samples with low pathogen copy numbers failed to demonstrate single peak melt curves and a sigmoidal cycle curve indicative of a true positive sample (Szewczuk et al. 2010). The current MT-PCR assay was an experimental assay that demonstrated proof of principle, but also needs further validation to reach diagnostic potential. A validated multiplex panel PCR for canine vector-borne pathogens would be a highly valuable epidemiological tool, particularly for comparison across different laboratories and geographic regions as shown for other pathogens (Lau et al. 2010, Szewczuk et al. 2010).

Limited information exists about canine vector-borne disease in Saudi Arabia, with only two case reports demonstrating the presence of endemic infections with $E$. canis and D. repens (Tarello 2003, Sacchini et al. 2007). The presence of additional canine vector-borne disease agents in dogs from Saudi Arabia is likely, despite the negative outcomes from the present study.

This study has confirmed the presence of $H$. dromedarii and $R$. sanguineus s.l. ( $R$. turanicus and $R$. cf. camicasi) on both dogs and camels and shows that dogs are more commonly parasitised by Hyalomma spp. than Rhipicephalus sp.. in Saudi Arabia, central Arabian Peninsula. There is a need for greater understanding of the diversity of $R$. sanguineus s.l. on a global scale with consistent reporting of morphology with deposited vouchers and molecular markers. There is an urgent need for taxonomists and tick experts alike to marry the morphology of $R$. sanguineus s.l. with the described genetic lineages (Nava et al. 2018).

Acknowledgements. This project was in part supported by Shaqra University, Saudi Arabia, the Twasol Research Excellence Program (TRE Program), King Saud University, Riyadh, Saudi Arabia. We would like to thank Maira Meggiolaro, Veterinary Pathology Diagnostic Services, University of Sydney, for excellent technical assistance. We acknowledge and thank Andrew and Janet von Berky, Von Berky Veterinary Services (VBVS) for supplying us with the laboratory-raised Rhipicephalus sanguineus of the "Coominya" strain, maintained by the Investigators VBVS as a colony, using dogs as hosts. The authors acknowledge the facilities and the scientific and technical assistance of the Australian Microscopy \& Microanalysis Research Facility at the Australian Centre for Microscopy \& Microanalysis, University of Sydney.

\section{REFERENCES}

Abdel-Shafy S., Allam N.A.T., Mediannikov O., Parola P., Raoult D. 2012: Molecular detection of spotted fever group rickettsiae associated with ixodid ticks in Egypt. Vector Borne Zoonotic Dis. 12: 346-359.

Aktas M., Ozubek S., Altay K., Ipek N.D., Balkaya I., Utuk A.E., Kirbas A., Simsek S., Dumanli N. 2015: Molecular detection of tick-borne rickettsial and protozoan pathogens in domestic dogs from Turkey. Parasit. Vectors 8: 157.

Apanaskevich D.A., HoraK I.G. 2008: The genus Hyalomma Koch, 1844: V. Re-evaluation of the taxonomic rank of taxa comprising the H. (Euhyalomma) marginatum Koch complex of species (Acari: Ixodidae) with redescription of all parasitic stages and notes on biology. Int. J. Acarol. 34: 13-42.
Apanaskevich D., Horak I. 2009: The genus Hyalomma Koch, 1844. IX. Redescription of all parasitic stages of H. (Euhyalomma) impeltatum Schulze \& Schlottke, 1930 and H. (E.) somalicum Tonelli Rondelli, 1935 (Acari: Ixodidae). Syst. Parasitol. 73: 199-218.

Apanaskevich D.A., Horak I.G. 2010: The genus Hyalomma. XI. Redescription of all parasitic stages of $H$. (Euhyalomma) asiaticum (Acari: Ixodidae) and notes on its biology. Exp. Appl. Acarol. 52: 207-220.

Apanaskevich D.A., Schuster A.L., Horak I.G. 2008: The genus Hyalomma: VII. Redescription of all parasitic stages of H. (Euhyalomma) dromedarii and $H$. (E.) schulzei (Acari: Ixodidae). J. Med. Entomol. 45: 817-831. 
Baneth G.A.D., Samish M., Alekseev E., Aroch I., Shkap V. 2001: Transmission of Hepatozoon canis to dogs by naturally-fed or percutaneously-injected Rhipicephalus sanguineus ticks. J. Parasitol. 87: 606-611.

Barker E.N., Langton D.A., Helps C.R., Brown G., Malik R., Shaw S.E., TASker S. 2012: Haemoparasites of free-roaming dogs associated with several remote Aboriginal communities in Australia. BMC Vet. Res. 8: 55.

BARker S.C., WALker A.R. 2014: Ticks of Australia: the species that infest domestic animals and humans. Zootaxa 3816: 1-144.

Beati L., Keirans J.E. 2001: Analysis of the systematic relationships among ticks of the genera Rhipicephalus and Boophilus (Acari: Ixodidae) based on mitochondrial $12 \mathrm{~S}$ ribosomal DNA gene sequences and morphological characters. J. Parasitol. 87: $32-48$.

Black W.C., Piesman J. 1994: Phylogeny of hard- and soft-tick taxa (Acari: Ixodida) based on mitochondrial $16 \mathrm{~S}$ rDNA sequences. Proc. Natl. Acad. Sci. U.S.A. 91: 10034-10038.

Brown G.K., Martin A.R., Roberts T.K., Aitken R.J. 2001: Detection of Ehrlichia platys in dogs in Australia. Aust. Vet. J. 79: 554-558.

Burger T.D., Shao R., Barker S.C. 2014: Phylogenetic analysis of mitochondrial genome sequences indicates that the cattle tick, Rhipicephalus (Boophilus) microplus, contains a cryptic species. Mol. Phylogenet. Evol. 76: 241-253.

Chitimia-Dobler L., Langguth J., Pfeffer M., Kattner S. Küpper T., Friese D., Dobler G., Guglielmone A.A., Nava S. 2017: Genetic analysis of Rhipicephalus sanguineus sensu lato ticks parasites of dogs in Africa north of the Sahara based on mitochondrial DNA sequences. Vet. Parasitol. 239: 1-6.

Cutler S.J. 2010: Relapsing fever - a forgotten disease revealed. J. Appl. Microbiol. 108: 1115-1122.

Dantas-Torres F., Latrofa M.S., Annoscia G., Giannelli A., Parisi A., Otranto D. 2013: Morphological and genetic diversity of Rhipicephalus sanguineus sensu lato from the New and Old Worlds. Parasit. Vectors 6: 213.

Dantas-Torres F., Maia C., Latrofa M.S., Annoscia G., Cardoso L., Otranto D. 2017: Genetic characterization of Rhipicephalus sanguineus (sensu lato) ticks from dogs in Portugal. Parasit. Vectors 10: 133

Elghali A., Hassan S.M. 2010: Life cycle of the camel tick Hyalomma dromedarii (Acari: Ixodidae) under field conditions in northern Sudan. Vet. Parasitol. 174: 305-312.

Estrada-Peña A., Pfäffle M.P., Petney T.N. 2017: Genus Hyalomma Koch, 1844. In: A. Estrada-Peña, M.P. Pfäffle and T.N. Petney (Eds), Ticks of Europe and North Africa: A Guide to Species Identification. Springer Nature, Cham, Switzerland, pp. 343-404.

de la Fuente J., Antunes S., Bonnet S., Cabezas-Cruz A., Domingos A.G., Estrada-Pena A., Johnson N., Kocan K.M., Mansfield K.L., Nijhof A.M., Papa A., Rudenko N., Villar M., Alberdi P., Torina A., Ayllon N., Vancova M., Golovchenko M., Grubhoffer L., Caracappa S. Fooks A.R., Gortazar C., Rego R.O.M. 2017: Tick-pathogen interactions and vector competence: identification of molecular drivers for tick-borne diseases. Front. Cell. Infect. Microbiol. 7: 114.

General Authority for Statistics 2014: Agriculture Statistical Year Book, Vol. 27. Ministry of Agriculture, Jeddah, Saudi Arabia, $210 \mathrm{pp}$.

General Authority of Meteorology \& Environmental Protection (Ed.) 2016: Presidency of Meterology and Environment (PME). http://www.pme.gov.sa

Guglielmone A.A., Robbins R.G., Apanaskevich D.A., Petney T.N., Estrada-Peña A., Horak I.G. 2013: The Hard Ticks of the World (Acari: Ixodida: Ixodidae). Springer Science $\&$ Business Media, Dordrecht, Netherlands, 738 pp.

Harrus S., Perlman-Avrahami A., Mumcuoglu K.Y., MorICK D., Eyal O., Baneth G. 2011: Molecular detection of Ehrlichia canis, Anaplasma bovis, Anaplasma platys, Candidatus
Midichloria mitochondrii and Babesia canis vogeli in ticks from Israel. Clin. Microbiol. Infect. 17: 459-463.

Hebert P.D.N., Cywinska A., Ball S.L., Dewaard J.R. 2003: Biological identifications through DNA barcodes. Proc. R. Soc. Biol. Sci. 270: 313-321.

Hebert P.D.N., Penton E.H., Burns J.M., Janzen D.H., Hallwachs W. 2004: Ten species in one: DNA barcoding reveals cryptic species in the neotropical skipper butterfly Astraptes fulgerator. Proc. Natl. Acad. Sci. U.S.A. 101: 14812-14817.

HekimoĞlu O., SaĞlam İ.K., Özer N., Estrada-PeÑa A. 2016: New molecular data shed light on the global phylogeny and species limits of the Rhipicephalus sanguineus complex. Ticks Tick Borne Dis. 7: 798-807.

Hit S.F., Traub R.J., Thompson M.F., Henning J., O’Leary C.A., Burleigh A., McMahon S., Rees R.L., Kopp S.R. 2015: Canine tick-borne pathogens and associated risk factors in dogs presenting with and without clinical signs consistent with tick-borne diseases in northern Australia. Aust. Vet. J. 93: $58-66$.

Hoogstraal H. 1956: African Ixoidea, Ticks of the Sudan, Vol. 1. Department of the Navy, Washington, USA, $1101 \mathrm{pp}$.

Hoogstraal H., Wassef H.Y., Büttiker W. 1981: Ticks (Acarina) of Saudi Arabia: Fam. Argasidae, Ixodidae. In: W. Wittmer and W. Büttiker (Eds), Fauna of Saudi Arabia. Pro Entomologia c/o Natural History Museum, Ciba-Geigy Ltd., Basel, Switzerland, pp. 25-110.

Jongejan F., Uilenderg G. 2004: The global importance of ticks. Parasitology 129: S3-S14.

Kaiser M.N., Hoogstraal H. 1963: The Hyalomma ticks (Ixodoidea, Ixodidae) of Afghanistan. J. Parasitol. 49: 130-139.

Kaiser M.N., Hoogstraal H. 1964: The Hyalomma ticks (Ixodoidea, Ixodidae) of Pakistan, India and Ceylon, with keys to subgenera and species. Acarologia 6: 257-286.

Kernif T., Djerbouh A., Mediannikov O., Ayach B., Rolain J.-M., Raoult D., Parola P., Bitam I. 2012: Rickettsia africae in Hyalomma dromedarii ticks from sub-Saharan Algeria. Ticks Tick Borne Dis. 3: 377-379.

Kumar S., Stecher G., Tamura K. 2016: MEGA7: Molecular Evolutionary Genetics Analysis version 7.0 for bigger datasets. Mol. Biol. Evol. 33: 1870-1874.

Kushimo O.M. 2013: The tick genus Amblyomma in Africa: phylogeny and mutilocus DNA barcoding. Electronic Thesis and Dissertations. Georgia Southern University, Statesboro, United States of America, 825, $23 \mathrm{pp}$

lau A., Halliday C., Chen S.C., Playford E.G., Stanley K., Sorrell T.C. 2010: Comparison of whole blood, serum and plasma for early detection of candidemia by multiplex-tandem PCR. J. Clin. Microbiol. 48: 811-816.

LEESON H.S. 1951: The recorded distribution of the tick Rhipicephalus sanguineus (Latreille). Bull. Entomol. Res. 42: 123-124.

Levin M.L., Studer E., Killmaster L., Zemtsova G., MumcUOGLU K.Y. 2012: Crossbreeding between different geographical populations of the brown dog tick, Rhipicephalus sanguineus (Acari: Ixodidae). Exp. Appl. Acarol. 58: 51-68.

Low V.L., PraKash B.K. 2018: First genetic characterization of the brown dog tick Rhipicephalus sanguineus sensu lato in Peninsular Malaysia. Exp. Appl. Acarol. 75: 299-307.

Low V.L., Tay S.T., Kho K.L., Кoh F.X., Tan T.K., Lim Y.A.L., Ong B.L., Panchadcharam C., Norma-Rashid Y., SofiAN-AzIRUn M. 2015: Molecular characterisation of the tick $R h$ ipicephalus microplus in Malaysia: new insights into the cryptic diversity and distinct genetic assemblages throughout the world. Parasit. Vectors 8: 341.

Lv J., Wu S., Zhang Y., Chen Y., Feng C., Yuan X., Jia G., Deng J., Wang C., Wang Q., Mei L., Lin X. 2014: Assessment of four DNA fragments (COI, 16S rDNA, ITS2, 12S rDNA) for species identification of the Ixodida (Acari: Ixodida). Parasit. Vectors 7: 93-93.

Marie J.L., Shaw S.E., Langton D.A., Bourry O., Gomez J., Davoust B. 2009: Sub-clinical infection of dogs from the Ivory 
Coast and Gabon with Ehrlichia, Anaplasma, Mycoplasma and Rickettsia species. Clin. Microbiol. Infect. 15: 284-285.

Morel P.C., Mouchet J., Rodhain F. 1976: Description de Rhipicephalus camicasi $\mathrm{n}$. sp. (Acariens, Ixodida) des steppes subdésertiques de la plaine Afar Somatie. Rev. Elev. Med. Vet. Pays Trop. 29: 337.

Nava S., Beati L., Venzal J.M., Labruna M.B., Szabó M.P.J., Petney T., Saracho-Bottero M.N., Tarragona E.L., Dantas-Torres F., Silva M.M.S., Mangold A.J., GuglielMONe A.A., Estrada-PeÑa A. 2018: Rhipicephalus sanguineus (Latreille, 1806): neotype designation, morphological re-description of all parasitic stages and molecular characterization. Ticks Tick Borne Dis. 9: 1573-1585.

Nava S., Mastropaolo M., Venzal J.M., Mangold A.J., Guglielmone A.A. 2012: Mitochondrial DNA analysis of $R h i$ picephalus sanguineus sensu lato (Acari: Ixodidae) in the Southern Cone of South America. Vet. Parasitol. 190: 547-555.

Nazari M., Lim S.Y., Watanabe M., Sharma R.S., Cheng N.A., Watanabe M. 2013: Molecular detection of Ehrlichia canis in dogs in Malaysia. PLoS Negl. Trop. Dis. 7: e1982.

Nguyen C., Koh W.L., Casteriano A., Beijerink N., Godfrey C., Brown G., Emery D., Šlapeta J. 2016: Mosquito-borne heartworm Dirofilaria immitis in dogs from Australia. Parasit. Vectors 9: 535 .

Oliveira L., Cardozo G., Santos E., Mansur M., Donini I., Zissou V., Roberto P., Marins M. 2009: Molecular analysis of the rRNA genes of Babesia spp. and Ehrlichia canis detected in dogs from Ribeirão Preto, Brazil. Braz. J. Microbiol. 40: 238-240.

Otranto D., Dantas-Torres F., Weigl S., Latrofa M.S., Stanneck D., Decapraris D., Capelli G., Baneth G. 2011: Diagnosis of Hepatozoon canis in young dogs by cytology and PCR. Parasit. Vectors 4: 55.

Panetta J.L., Šíma R., Calvani N.E.D., Hajdušek O., ChandRa S., Panuccio J., Šlapeta J. 2017: Reptile-associated Borrelia species in the goanna tick (Bothriocroton undatum) from Sydney, Australia. Parasit. Vectors 10: 616.

Pegram R.G., Hoogstraal H., Wassef H.Y. 1982a: Hyalomma (Hyalommina) arabica $\mathrm{sp}$. n. parasitizing goats and sheep in the Yemen Arab Republic and Saudi Arabia. J. Parasitol. 68: $150-156$.

Pegram R.G., Hoogstraal H., Wassef H.Y. 1982b: Ticks (Acari: Ixodoidea) of the Yemen Arab Republic. I. Species infesting livestock. Bull. Entomol. Res. 72: 215-227.

Pegram R.G., Keirans J.E., Clifford C.M., Walker J.B. 1987: Clarification of the Rhipicephalus sanguineus group (Acari, Ixodoidea, Ixodidae). II. R. sanguineus (Latreille, 1806) and related species. Syst. Parasitol. 10: 27-44.

Pegram R.G., Walker J.B. 1988: Clarification of the biosystematics and vector status of some African Rhipicephalus species (Acarina: Ixodidae). In: M.W. Service (Ed.), Biosystematics of Haematophagous Insects. Clarendon Press, Oxford, England, pp. 61-76.

Rees D.J., Dioli M., Kirkendall L.R. 2003: Molecules and morphology: evidence for cryptic hybridization in African $\mathrm{Hy}$ alomma (Acari: Ixodidae). Mol. Phylogenet. Evol. 27: 131-142.
Roberts F.H.S. 1970: Australian Ticks. Commonwealth Scientific and Industrial Research Organisation, Melbourne, Australia, $267 \mathrm{pp}$.

Rzhetsky A., Nei M. 1992: A simple method for estimating and testing minimum-evolution trees. Mol. Biol. Evol. 9: 945-967.

Sacchini F., Cessford R.J., Robinson B.M. 2007: Outbreak of canine monocytic ehrlichiosis in Saudi Arabia. Vet. Clin. Pathol. 36: $331-335$.

Sands A.F., Apanaskevich D.A., Matthee S., Horak I.G., Harrison A., Karim S., Mohammad M.K., Mumcuoglu K.Y., Rajakaruna R.S., Santos-Silva M.M., Matthee C.A. 2017: Effects of tectonics and large scale climatic changes on the evolutionary history of Hyalomma ticks. Mol. Phylogenet. Evol. 114: 153-165.

Santos F., Coppede J.S., Pereira A.L., Oliveira L.P., Roberto P.G., Benedetti R.B., Zucoloto L.B., Lucas F., SobreiRA L., Marins M. 2009: Molecular evaluation of the incidence of Ehrlichia canis, Anaplasma platys and Babesia spp. in dogs from Ribeirão Preto, Brazil. Vet. J. 179: 145-148.

Seneviratna P., Weerasinghe, Ariyadasa S. 1973: Transmission of Haemobartonella canis by the dog tick, Rhipicephalus sanguineus. Res. Vet. Sci. 14: 112-114.

Sergeant E. 2017. Epitools epidemiological calculators. http://epitools.ausvet.com.au (Ausvet Pty Ltd.).

ŠLaPeTA Š., ŠLaPeTA J. 2016: Molecular identity of cat fleas (Ctenocephalides felis) from cats in Georgia, USA carrying Bartonella clarridgeiae, Bartonella henselae and Rickettsia sp. RF2125. Vet. Parasitol. Reg. Stud. Reports 3: 36-40.

Stanley K.K., Szewczuk E. 2005: Multiplexed tandem PCR: gene profiling from small amounts of RNA using SYBR Green detection. Nucleic Acids Res. 33: e180.

Szabó M.P.J., Mangold A.J., João C.F., Bechara G.H., Guglielmone A.A. 2005: Biological and DNA evidence of two dissimilar populations of the Rhipicephalus sanguineus tick group (Acari: Ixodidae) in South America. Vet. Parasitol. 130: 131-140.

Szewczuk E., Thapa K., Anninos T., McPhie K., Higgins G., Dwyer D.E., Stanley K.K., Iredell J.R. 2010: Rapid semi-automated quantitative multiplex tandem PCR (MT-PCR) assays for the differential diagnosis of influenza-like illness. BMC Infect. Dis. 10: 113.

Tajima F., Nei M. 1984: Estimation of evolutionary distance between nucleotide sequences. Mol. Biol. Evol. 1: 269-285.

Tarello W. 2003: Dermatitis associated with Dirofilaria repens microfilariae in three dogs in Saudi Arabia. J. Small Anim. Pract. 44: 132-134.

Vascellari M., Ravagnan S., Carminato A., Cazzin S., Carli E., Da Rold G., Lucchese L., Natale A., Otranto D., Capelli G. 2016: Exposure to vector-borne pathogens in candidate blood donor and free-roaming dogs of northeast Italy. Parasit. Vectors 9: 369.

Walker J.B., Horak I., Keirans J.E. 2005: The Genus Rhipicephalus (Acardi, Ixodidae): A Guide to the Brown Ticks of the World, Second Edition. Cambridge University Press, New York, USA, $656 \mathrm{pp}$ sensu lato from dogs and dromedary camels in Riyadh, Saudi Arabia: low prevalence of vector-borne pathogens in dogs detected using multiplexed tandem PCR panel. Folia Parasitol. 66: 007. 